\title{
Detecting toxin genes of Clostridium perfringens isolated from diarrhea piglets using multiplex PCR
}

\author{
Dung H. M. Nguyen ${ }^{1}$, Quynh T. X. Luong ${ }^{1}$, Phuong T. Hoang ${ }^{2}$, Duong T. T. Do ${ }^{1}$, \\ Thoai K. Tran ${ }^{1}$, \& Phat X. Dinh ${ }^{1 *}$ \\ ${ }^{1}$ Department of Biotechnology, Nong Lam University, Ho Chi Minh City, Vietnam \\ ${ }^{2}$ Vinh An Science and Technology Company Limited, Ho Chi Minh City, Vietnam
}

\author{
ARTICLE INFO \\ Research Paper \\ Received: September 15, 2018 \\ Revised: October 29, 2018 \\ Accepted: November 11, 2018
}

\section{Keywords}

Clostridium perfringens (C. perfringens) Multiplex PCR (mPCR)

Piglet diarrhea

Piglets

\section{* Corresponding author}

Dinh Xuan Phat

Email: dinhxuanphat@hcmuaf.edu.vn

\begin{abstract}
Clostridium perfringens is currently classified into five types (A, B, C, D, E) based on the different toxins produced. Type $\mathrm{A}$ and $\mathrm{C}$ are known as the causative agent of enteritis and enterotoxemia in newborn and young piglets with severe intestinal lesions including edema, hemorrhage and necrosis. A multiplex PCR (mPCR) was developed in order to quickly and early determine the presence of genotypes of $C$. perfringens based on their genes of $c p a, c p b, c p b 2$ and $c p e$ encoding alpha toxin, beta toxin, beta 2 toxin and enterotoxin with predicted products of $324 \mathrm{bp}, 196 \mathrm{bp}, 107 \mathrm{bp}$ and $257 \mathrm{bp}$ respectively.

The detection limit of the mPCR assay was $1 \times 10^{3}$ copies/reaction for each gene. Sequencing of mPCR products performed with clinical samples collected from C. perfringens suspected pigs showed that the mPCR test functioned specifically. In conclusion, the developed mPCR test successfully detected the presence of genes $c p a, c p b, c p b 2$ and $c p e$ in the examined samples. Analysis of the bacteria isolated from field samples of diarrheal piglets collected in this study indicated that $C$. perfringens carrying gene cpa counted for $96.66 \%$ and $3.33 \%$ was identified as C. perfringens carrying genes cpa and $c p b$ concurrently. Gene cpe was not found in this study, while gene cpb2 was detected coincidently in $73.33 \%$ of the samples with cpa gene. The results indicate that the prevalence of these four toxin genes is $c p a, c p b 2, c p b$ and $c p e$ in decending order.
\end{abstract}

Cited as: Nguyen, D. H. M., Luong, Q. T. X., Hoang, P. T., Do, D. T. T., Tran, T. K., \& Dinh, P. X. (2018). Detecting toxin genes of Clostridium perfringens isolated from diarrhea piglets using multiplex PCR. The Journal of Agriculture and Development 17(6), 24-30.

\section{Introduction}

Diarrhea neonatal piglets is one of the most causes of economic losses in the swine industry. Among the common infectious agents, Clostridium perfringens ( $C$. perfringens) plays a key role in enteric diseases not only in domestic animals but also in humans. C. perfringens is a Grampositive, anaerobic, rod-shaped bacterium. It is known to produce various toxins including alpha $(\alpha)$, beta $(\beta)$, epsilon $(\varepsilon)$, and iota $(\iota)$. These tox- ins play important roles in the pathogenesis of the disease and are used to classify $C$. perfringens into five biotypes, designated A-E. These five types can be subdivided according to the production of two additional toxins: the enterotoxin (encoded by the cpe gene) and the $\beta_{2}$ toxin (encoded by cpb2 gene) and described in Table 1 . Type A and C strains cause diarrhea, dysentery and enterotoxaemia in pigs (Lebrun et al., 2010; Markey et al., 2013).

Conventional isolation on agar media usually 
Table 1. Clostridium perfringens conventional toxinotypes (Leburn et al., 2010; Mcclane et al., 2006)

\begin{tabular}{|c|c|c|c|c|c|c|}
\hline Genes & Toxin & Type A & Type B & Type C & Type D & Type E \\
\hline$c p a$ & $\alpha$ & $\mathrm{X}$ & $\mathrm{X}$ & $\bar{X}$ & $\mathrm{X}$ & $\mathrm{X}$ \\
\hline$c p b$ & $\beta$ & & $\mathrm{X}$ & $\mathrm{X}$ & & \\
\hline etx & $\varepsilon$ & & $\mathrm{X}$ & & $\mathrm{X}$ & \\
\hline$i a p / i b p$ & $\iota$ & & & & & $\mathrm{X}$ \\
\hline сре & Enterotoxin (X) & & & & & $(\mathrm{X})$ \\
\hline cpb2 & $\beta_{2}$ & $(\mathrm{X})$ & $(\mathrm{X})$ & $(\mathrm{X})$ & $(\mathrm{X})$ & $(\mathrm{X})$ \\
\hline Host & & $\begin{array}{c}\text { Pigs, } \\
\text { humans, } \\
\text { lambs, } \\
\text { dogs, } \\
\text { chickens }\end{array}$ & $\begin{array}{c}\text { Lambs } \\
\text { (under } 3 \\
\text { weeks old), } \\
\text { neonatal } \\
\text { calves, foals }\end{array}$ & $\begin{array}{c}\text { Piglets, } \\
\text { lambs, } \\
\text { calves, } \\
\text { foals, } \\
\text { adult } \\
\text { sheep, } \\
\text { chickens }\end{array}$ & $\begin{array}{c}\text { Sheep } \\
\text { (all ages, } \\
\text { except } \\
\text { neonates), } \\
\text { (goats, } \\
\text { calves) }\end{array}$ & $\begin{array}{l}\text { Calves, } \\
\text { rabbits }\end{array}$ \\
\hline
\end{tabular}

X Classic; (X) Potential.

takes longer time in routine diagnostic process. In this study, a multiplex PCR (mPCR) protocol was developed to determine the presence of toxin genes coding for alpha toxin (cpa), beta toxin $(c p b)$, enterotoxin (cpe) and beta2 toxin (cpb2) of $C$. perfringens isolates.

\section{Materials and Methods}

\subsection{Control and clinical samples}

Positive control: DNA fragments of $c p b$ gene (beta toxin) and cpe gene (enterotoxin) were synthesized by IDT (Integrated DNA Technologies USA); and C. perfringens reference strains contained cpa gene (alpha toxin) and cpb2 gene $\left(\beta_{2}\right.$ toxin) were supplied by Sanphar Vietnam laboratory (belonging to Erber group, Austria). The presence of $c p a$ and $c p b 2$ in this positive control sample was confirmed by sequencing. The resultant sequences of cpa and cpb2 has $97-100 \%$ identity to the Genbank Id MH213493.1 and MG720638.1, respectively.

Negative control: viruses and bacteria potentially found in intestinal or fecal samples including Salmonella spp., E. coli (ATCC 25922), obtained from Sanphar's laboratory. Salmonella spp. was isolated from the field and identified by culture method as well as biochemical reaction; colonies of Streptococcus suis and a sample containing DNA of PCV2 virus confirmed by sequencing were obtained from the laboratory of Animal Molecular Pathogenesis and the Gene Technology laboratory respectively at the
Department of Biotechnology, Nong Lam University, Ho Chi Minh City, Vietnam.

Clinical samples: Thirty isolates of C. perfringens were selected from different samples of anal swabs or feces taken from piglets $(<25$ days of age) having the symptoms or lesions of: $1 /$ sudden death or dying shortly after bloody diarrhea; 2/ diarrhea; 3/ diarrhea with blood or necrotic patches of tissues;4/ Dead piglets usually have bulging stomach and/or intestines; 5/ Haemorrhagic and/or necrotic intestinal mucosa.

\subsection{Isolation of total DNA}

Clostridium perfringens isolates were collected from clinical samples (feces and swab samples from C. perfringens - suspected pigs with the symptoms described above) using blood agar medium (Cat\#M975A, Himedia) in anaerobic condition and these colonies were determined as C. perfringens by morphology. After 24 to 48 hours of culture at $37^{0} \mathrm{C}$, these colonies appeared with round, smooth and glossy shapes, covered by a double hemolysis, complete hemolysis inner zone and partial hemolysis outer zone. Suspected colonies were further confirmed by biochemical reactions on gelatin medium to test sugar fermentation, nitrate to nitrite transfer and negative catalase test (Markey et al., 2013). Then, TPGY (Tryptone Peptone Glucose Yeast extract) (Cat\#M969, Himedia) broth was used as an enrichment broth for obtaining a high rate of bacterial biomass. Thus, cells from $50 \mathrm{~mL}$ of overnight cultures of TPGY broth were harvested by cen- 
trifugation at $13,000 \mathrm{rpm}$ for $10 \mathrm{~min}$ at $4^{0} \mathrm{C}$. The cells were washed in $5 \mathrm{~mL}$ of $1 \mathrm{X}$ PBS $\mathrm{pH} 7.0$ (Cat\#10010023, Gibco), centrifuged and resuspended in $1 \mathrm{~mL}$ of the same buffer. Twenty microliters of the solution mixture with $300 \mu \mathrm{L}$ TEN buffer (20mM Tris-HCl, 5mM EDTA, $140 \mathrm{mM}$ $\mathrm{NaCl}, \mathrm{pH} 8.0)$ and $30 \mu \mathrm{L}$ lysozyme $(10 \mathrm{ng} / \mu \mathrm{L})$ (Cat\#90082, Thermo Fisher Scientific). The solution was incubated at $37^{0} \mathrm{C}$ for $15 \mathrm{~min}$. After incubation of the mixture with $30 \mu \mathrm{L}$ of SDS $20 \%$ solution at $37^{0} \mathrm{C}$ for $15 \mathrm{~min}$, the bacterial DNA was extracted with phenol-chloroformisoamyl alcohol (25:24:1) solution (Cat\#P1037, Sigma; Cat\#25666, Merck). The tubes were kept inverted then still in $5 \mathrm{~min}$ and centrifugation at $13,000 \mathrm{rpm}$ for $10 \mathrm{~min}$. The upper aqueous layer was recovered for DNA precipitation with $900 \mu \mathrm{L}$ ethanol $100 \%$ at $-20^{\circ} \mathrm{C}$ overnight. The DNA was pelleted, washed with $70 \%$ ethanol, allowed to dry and dissolved in $40 \mu \mathrm{L}$ TE, $\mathrm{pH}$ 8.0. Extracted DNA was stored at $-20^{\circ} \mathrm{C}$ until being used. Two microliters were used in each $\mathrm{mPCR}$ reaction.

\subsection{Primer design}

Primer pairs CPA (encoding alpha toxin), and CPB (encoding beta toxin) were adopted from Meer and Songer (Meer et al., 1997). Besides, CPE (encoding enterotoxin) and CPB2 (encoding $\beta_{2}$ toxin) primers were designed by Primer3plus (http://primer3plus.com/cgi$\mathrm{bin} / \mathrm{dev} /$ primer3plus.cgi) using the sequence data of cpe gene and cpb2 gene obtained from NCBI (Table 2), and validated by NCBI BLAST, OligoAnalyzer 1.0.2. The annealing temperature and the size of the amplified product were adjusted to become appropriate to be combined with the two adopted primer pairs in a new mPCR. Primers were synthesized by IDT (Integrated DNA Technologies - USA).

\subsection{Single PCR (sPCR) optimization}

All primers were initially tested using gradient single PCRs according to the product specifications and protocols. The sPCR was performed in a $30 \mu \mathrm{l}$ reaction mixture containing $1 \mu \mathrm{L}$ DNA template, $0.33 \mu \mathrm{M}$ each primer, $15 \mu \mathrm{L}$ DreamTaq master mix 2X (Cat\#K1081, Thermo Fisher Scientific), and nuclease-free water to adjust the final volume to $30 \mu \mathrm{L}$ (Cat\#R0582, Thermo Fisher Scientific). Nuclease-free water was also used as a negative control for all PCRs. The PCR was 
carried out for pre-denaturation at $95^{0} \mathrm{C}$ for 5 minutes, 35 cycles consisting of denaturation for 30 seconds at $95^{\circ} \mathrm{C}$, annealing at a temperature range for the gradient PCR: $53^{0} \mathrm{C}, 55^{0} \mathrm{C}, 57^{0} \mathrm{C}$, $59^{0} \mathrm{C}, 61^{0} \mathrm{C}$ for 30 seconds, extension for $70 \mathrm{sec}-$ onds at $72^{0} \mathrm{C}$ and a final extension of $72^{0} \mathrm{C}$ for 10 minutes (model TC-512 GeneAmp PCR System; England). Ten microliters of amplified products were then analyzed by electrophoresis in a $2 \%(\mathrm{w} / \mathrm{v})$ agarose gel in $1 \mathrm{X}$ Tris-acetate-EDTA (TAE) with Midori Green Advance DNA stain (Cat\#AG10, Nippon) using $1 \mathrm{~kb}$ Plus DNA ladder (Cat\#10787018, Invitrogen) as the molecular weight markers to indicate the sizes of the amplification products.

\subsection{Multiplex PCR (mPCR)}

After several rounds of optimization, four ratios of each primer were investigated. Finally, a primer mix including the four primer pairs was generated with a ratio of CPA:CPB:CPE:CPB2 to be $0.67 \mu \mathrm{M}$ : $0.33 \mu \mathrm{M}: 0.67 \mu \mathrm{M}: 1.0 \mu \mathrm{M}$ respectively. The annealing temperature of $\mathrm{mPCR}$ was $57^{0} \mathrm{C}$ to detect equal signal for each PCR product. The final $\mathrm{mPCR}$ mix included $15 \mathrm{\mu l}$ of DreamTaq 2X primer concentration is used as mentioned above; $4 \mu \mathrm{L}$ DNA template mix; and nuclease-free water to adjust the final volume to $30 \mu \mathrm{L}$. The $\mathrm{mPCR}$ conditions were similar to those described for sPCRs. Gel electrophoresis was extended to 70 minutes at $60 \mathrm{~V}$ for better separation of the amplicons. After that, DNA fragments were recovered from low melting agarose using phenol-chloroform method and sequenced by University of Medicine and Pharmacy, Ho Chi Minh city, Vietnam. The sequences of the products were aligned with the target genes.

\subsection{Specificity and sensitivity of multiplex PCR}

In order to confirm the specificity of the mPCR conditions, genomic DNA of Salmonella spp., E. coli, Streptococcus suis, and PCV2 were used as negative controls in the $\mathrm{mPCR}$ reactions as described above. Regarding the sensitivity, synthesized DNA fragments of $c p b$ gene and cpe gene; and the purified PCR product of $c p a, c p b 2$ gene were used. These templates were diluted ten-fold serially in nuclease-free water and used for sensitivity test in the mPCR to estimate its limit of detection.

\section{Results and Discussion}

\subsection{Multiplex PCR}

In sPCRs, gel electrophoresis analysis confirmed the exact product size as predicted for each gene, including cpa - $324 \mathrm{bp}, c p b-196 \mathrm{bp}$, cpe - $257 \mathrm{bp}$, and cpb2 - $107 \mathrm{bp}$. The results also indicated that 4 pairs of primers worked well in the annealing temperature range of $55^{\circ} \mathrm{C}-61^{\circ} \mathrm{C}$, and the $57^{\circ} \mathrm{C}$ was chosen for mPCR. In addition, after the optimization of the mPCR, the products were clearly visible and easily distinguishable from each other, and sequencing of the four mPCR products showed that the MPCR functioned accurately (Figure 1).

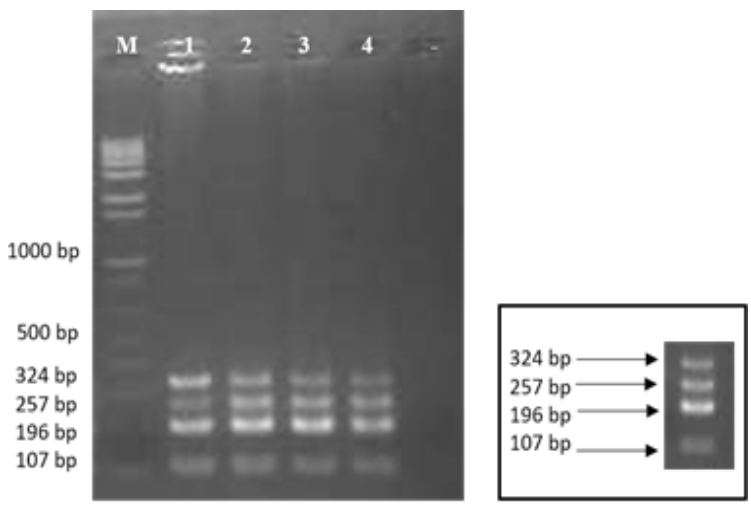

Figure 1. Results of the annealing temperature survey of multiplex PCR detecting four toxin genes of C. perfringens. cpa $-324 \mathrm{bp}, c p b-196 \mathrm{bp}$, cpe -257 bp, and cpb2 - 107 bp. M: 1 kb Plus ladder; (1) - (4): annealing temperature of $55^{\circ} \mathrm{C}, 57^{\circ} \mathrm{C}, 59^{\circ} \mathrm{C}, 61^{\circ} \mathrm{C}$, respectively; (-) negative control with pure water.

Figure 2a is a result of the sensitivity testing of the optimized mPCR showing the four clear products. The mPCR could detect all four bands with equal signals when the template concentration present at $1 \times 10^{3}$ copies/reaction.

Specificity test of the $\mathrm{mPCR}$ was performed with unrelated DNA from virus and bacteria commonly found in the intestine and feces of pigs including Salmonella spp., E. coli, Streptococcus suis, and PCV2 as the four negative controls. Results showed that no amplified products were seen. It means that four primer pairs do not crossreact with DNA from the investigated organisms, avoiding false-positive results (Figure 2b). 

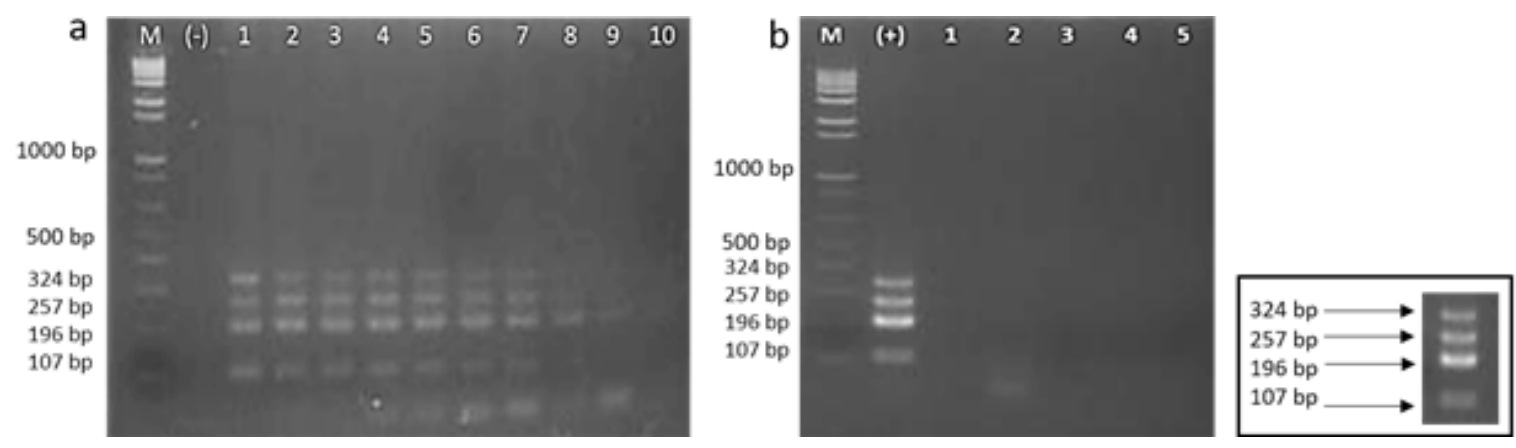

Figure 2. Multiplex PCR detecting four toxin genes of C. perfringens. cpa - 324 bp, cpb - 196 bp, cpe - 257 $\mathrm{bp}$, and cpb2 - $107 \mathrm{bp}$.

a. Sensitivity test. M: $1 \mathrm{~kb}$ Plus ladder; (-) negative control with pure water; (1) - (10): dilution starting from $1 \times 10^{9}$ to $1 \times 10^{0}$ DNA copies of each template.

b. Specificity test. (+): positive control; (1) - (4): negative controls (DNA of Salmonella spp., E. coli, Streptococcus suis, and PCV2 respectively); (5) negative control with pure water.
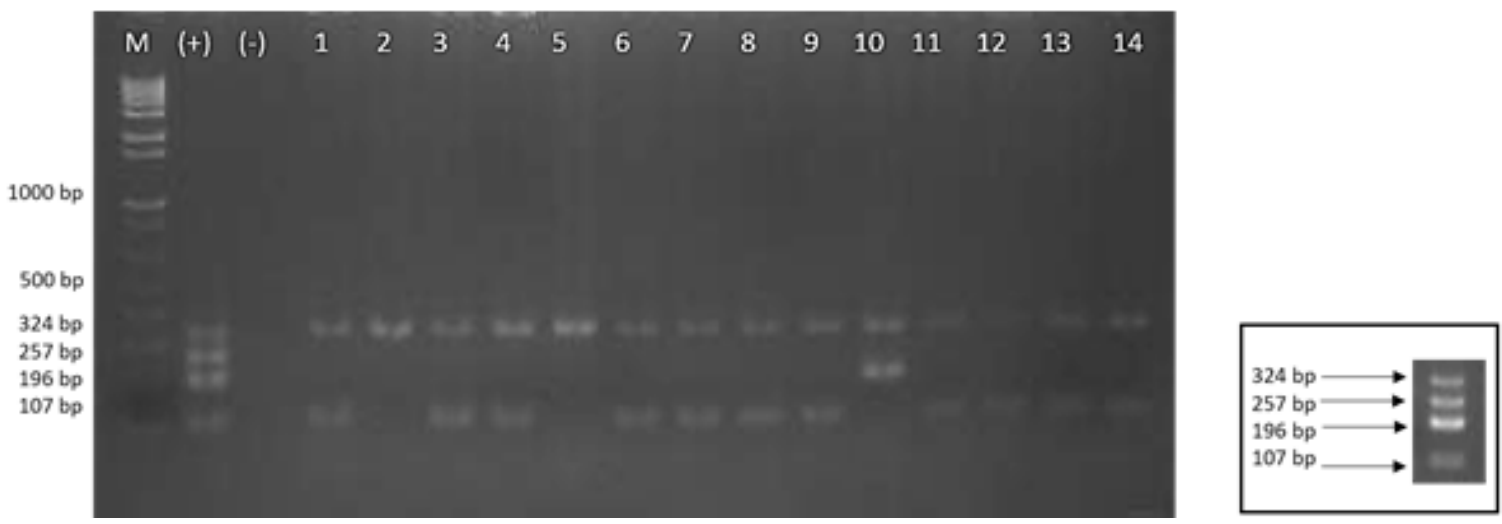

Figure 3. Multiplex PCR test using clinical samples.

M: $1 \mathrm{~kb}$ Plus ladder, (+) positive control, (-) negative control with pure water, (1) - (14) clinical samples.

\subsection{Detecting the presence of toxin genes from clinical samples}

The mPCR was evaluated using 30 colonies isolated from clinical samples of different farms suspected to be $C$. perfringens based on biochemical test following instruction by Markey et al. (2013). The results are summarized in Table 3 while Figure 3 showed the agarose gel analysis for mPCR products of 14 out of 30 isolates examined.

All 30 isolates were shown to carry the cpa gene (100\%), further confirming these isolates are $C$. perfringens even though this is not surprising, as gene cpa has been reported to be the dominant genes of $C$. perfringens in swine. Only one out of 30 samples $(3.33 \%)$, in the well number 10 showed positive for both alpha (cpa) and beta toxin (cpb) gene together (Figure 3). Recently, Yadav et al. (2017) also reported the presence of only $3 \% C$. perfringens carrying the cpa and $c p b$ gene from diarrheal cases in swine in India. Additionally, 22/30 isolates (73.33\%) positive for the cpa and cpb2 gene (encoding $\beta_{2}$ toxin) in the present study was similar to the detection rate (70\% - 90.3\%) from previous reports (Van Asten et al., 2010; Chan et al., 2012; Yadav et al., 2017 ). It has been shown that $\beta_{2}$ toxin may play a key role in enteric diseases of pigs, even though the issue is still controversial. On the other hand, none of the isolates tested in this examination was cpe-positive, this is in accordance with a previous study carried out in America with 89 samples (Kanakaj et al., 1998). In the present communication, according to the toxinotypes of Leburn 
Table 3. Results of mPCR detecting four toxin genes of thirty $C$. perfringens isolates from diarrheal piglets

\begin{tabular}{|c|c|c|c|c|}
\hline \multirow{2}{*}{ Isolate } & \multicolumn{4}{|c|}{ Genes (Toxin) } \\
\hline & $\operatorname{cpa}(\alpha)$ & $c p b(\beta)$ & cpe (Entero-toxin) & $c p b 2\left(\beta_{2}\right)$ \\
\hline 1 & $(+)$ & $(-)$ & $(-)$ & $(+)$ \\
\hline 2 & $(+)$ & $(-)$ & $(-)$ & $(-)$ \\
\hline 3 & $(+)$ & $(-)$ & $(-)$ & $(+)$ \\
\hline 4 & $(+)$ & $(-)$ & $(-)$ & $(+)$ \\
\hline 5 & $(+)$ & $(-)$ & $(-)$ & $(-)$ \\
\hline 6 & $(+)$ & $(-)$ & $(-)$ & $(+)$ \\
\hline 7 & $(+)$ & $(-)$ & $(-)$ & $(+)$ \\
\hline 8 & $(+)$ & $(-)$ & $(-)$ & $(+)$ \\
\hline 9 & $(+)$ & $(-)$ & $(-)$ & $(+)$ \\
\hline 10 & $(+)$ & $(+)$ & $(-)$ & $(-)$ \\
\hline 11 & $(+)$ & $(-)$ & $(-)$ & $(+)$ \\
\hline 12 & $(+)$ & $(-)$ & $(-)$ & $(+)$ \\
\hline 13 & $(+)$ & $(-)$ & $(-)$ & $(+)$ \\
\hline 14 & $(+)$ & $(-)$ & $(-)$ & $(+)$ \\
\hline 15 & $(+)$ & $(-)$ & $(-)$ & $(-)$ \\
\hline 16 & $(+)$ & $(-)$ & $(-)$ & $(-)$ \\
\hline 17 & $(+)$ & $(-)$ & $(-)$ & $(+)$ \\
\hline 18 & $(+)$ & $(-)$ & $(-)$ & $(+)$ \\
\hline 19 & $(+)$ & $(-)$ & $(-)$ & $(-)$ \\
\hline 20 & $(+)$ & $(-)$ & $(-)$ & $(-)$ \\
\hline 21 & $(+)$ & $(-)$ & $(-)$ & $(+)$ \\
\hline 22 & $(+)$ & $(-)$ & $(-)$ & $(+)$ \\
\hline 23 & $(+)$ & $(-)$ & $(-)$ & $(+)$ \\
\hline 24 & $(+)$ & $(-)$ & $(-)$ & $(+)$ \\
\hline 25 & $(+)$ & $(-)$ & $(-)$ & $(+)$ \\
\hline 26 & $(+)$ & $(-)$ & $(-)$ & $(+)$ \\
\hline 27 & $(+)$ & $(-)$ & $(-)$ & $(+)$ \\
\hline 28 & $(+)$ & $(-)$ & $(-)$ & $(+)$ \\
\hline 29 & $(+)$ & $(-)$ & $(-)$ & $(-)$ \\
\hline 30 & $(+)$ & $(-)$ & $(-)$ & $(+)$ \\
\hline
\end{tabular}

(+):Positive; (-):Negative.

et al. (2010) and Mcclane et al. (2006) (Table 1), $96.66 \%$ of the isolates showing positive for cpa can be considered as $C$. perfringens type A; $3.33 \%$ isolates positive for both $c p a$ and $c p b$ can be considered as C. perfringens type C; $73.33 \%$ isolates showing positive for $c p a$ and $c p b 2$ gene are $C$. perfringens type A carrying additional minor $c p b 2$ gene.

\section{Conclusions}

To summarize, the mPCR developed in this study enables the simultaneous detection of two major toxin genes $(c p a, c p b)$ and two minor toxin genes (cpe, cpb2) of $C$. perfringens. The optimal annealing temperature was $57^{0} \mathrm{C} / 30 \mathrm{~s}$. The ratio of primers CPA:CPB:CPE: CPB2 were 0.67 $\mu \mathrm{M}: 0.33 \mu \mathrm{M}: 0.67 \mu \mathrm{M}: 1.0 \mu \mathrm{M}$ respectively. The $\mathrm{mPCR}$ was specific and the sensitivity was at $1 \mathrm{x}$ $10^{3}$ copies/template per reaction. Thirty colonies isolated from clinical samples were tested to determine the presence of these toxin genes. Results showed that in this set of samples, the detection rate of $c p a, c p b, c p b 2$ and cpe was $100 \%, 3.33 \%$, $73.33 \%$ and $0 \%$ respectively. The results indicate that the prevalence of these four toxin genes is $c p a, c p b 2, c p b$ and $c p e$ in decending order. 


\section{References}

Chan, G., Farzan A., Soltes, G., Nicholson, V. M., Pei Y., Friendship, R., \& Prescott, J. F. (2012). The epidemiology of Clostridium perfringens type A on Ontario swine farms, with special reference to cpb2-positive isolates. BMC Veterinary Research, 8(1), 156.

Kanakaraj, R., Harris, D. L., Songer, J. G.,\& Bosworth, B., (1998). Multiplex PCR assay for detection of Clostridium perfringens in feces and intestinal contents of pigs and in swine feed. Veterinary microbiology 63(1), 29-38.

Lebrun, M., Mainil, J. G., \& Linden, A. (2010). Cattle enterotoxaemia and Clostridium perfringens: description, diagnosis and prophylaxis. Veterinary Record 167(1), 13-22.

Markey, B., Leonard, F., Archambault, M., Cullinane, A., \& Maguire, D. (2013). Clinical veterinary microbiology (2 $2^{\text {nd }}$ ed.). Edinburgh, UK: Mosby Elsevier.
Mcclane, B. A., Uzal, F. A., Miyakawa, M. E. F., Lyerly, D., \& Wilkins, T. (2006). The prokaryotes ( $3^{\text {rd }}$ ed.). New York, USA: Springer.

Meer, R. R., \& Songer, J. G. (1997). Multiplex polymerase chain reaction assay for genotyping Clostridium perfringens. American Journal of Veterinary Research 58(7), 702-705.

Van Asten, A. J., Nikolaou, G. N., \& Grone, A. (2010). The occurrence of cpb2-toxigenic Clostridium perfringens and the possible role of the $\beta_{2}$ toxin in enteric disease of domestic animals, wild animals and humans. The veterinary journal 183(2), 135-140.

Yadav, J. P., Das, S. C., Dhaka, P., Vijay, D., Kumar, M., Mukhopadhyay, A. K., Chowdhury G., Chauhan P., Singh R., Dhama K., Malik S., \& Kumar A. (2017). Molecular characterization and antimicrobial resistance profile of Clostridium perfringens type A isolates from humans, animals, fish and their environment. Anaerobe 47, 120-124. 